\title{
Identification and analysis of long non- coding RNAs and mRNAs in chicken macrophages infected with avian infectious bronchitis coronavirus
}

Hao Li $i^{1,2}$, Pengfei Cui ${ }^{1,2}$, Xue Fu' ${ }^{1,2}$, Lan Zhang ${ }^{1,2}$, Wenjun Yan ${ }^{1,2}$, Yaru Zhai ${ }^{1,2}$, Changwei Lei ${ }^{1,2}$, Hongning Wang ${ }^{1,2}$ and Xin Yang ${ }^{1,2^{*}}$ (i)

\begin{abstract}
Background: Avian infectious bronchitis virus (IBV) is a gamma coronavirus that severely affects the poultry industry worldwide. Long non-coding RNAs (IncRNAs), a subset of non-coding RNAs with a length of more than 200 nucleotides, have been recently recognized as pivotal factors in the pathogenesis of viral infections. However, little is known about the function of IncRNAs in host cultured cells in response to IBV infection.

Results: We used next-generation high throughput sequencing to reveal the expression profiles of mRNAs and IncRNAs in IBV-infected HD11 cells. Compared with the uninfected cells, we identified 153 differentially expressed (DE) mRNAs (106 up-regulated mRNAs, 47 down-regulated mRNAs) and 181 DE IncRNAs (59 up-regulated IncRNAs, 122 down-regulated IncRNAs) in IBV-infected HD11 cells. Moreover, gene ontology (GO) and pathway enrichment analyses indicated that DE mRNAs and IncRNAs were mainly involved in cellular innate immunity, amino acid metabolism, and nucleic acid metabolism. In addition, 2640 novel chicken IncRNAs were identified, and a competing endogenous RNA (ceRNAs) network centered on gga-miR-30d and miR-146a-5p was established.

Conclusions: We identified expression profiles of mRNAs and IncRNAs during IBV infection that provided new insights into the pathogenesis of IBV.
\end{abstract}

Keywords: IBV, IncRNA, HD11, Coronavirus, Chicken, Gga-miR-30d, miR-146a-5p

\section{Background}

Avian infectious bronchitis (IB) is a highly contagious viral disease of chicken caused by infectious bronchitis virus (IBV). The disease incurs huge economic losses to the poultry industry annually [1]. IBV belongs to the gamma coronaviruses family. Like other coronaviruses, IBV contains a $27.6 \mathrm{~kb}$ single-stranded, positive-sense

\footnotetext{
* Correspondence: yangxin0822@163.com

'Key Laboratory of Bio-Resources and Eco-Environment, Ministry of Education, College of Life Science, Sichuan University, Chengdu 610064, China

${ }^{2}$ Animal Disease Prevention and Food Safety Key Laboratory of Sichuan Province, Chengdu 610064, China
}

RNA genome, which encodes for polyproteins 1a and $1 \mathrm{~b}$, four structural proteins (the spike $[\mathrm{S}]$, envelope [E], membrane $[\mathrm{M}]$, and nucleocapsid $[\mathrm{N}]$ proteins), and several accessory proteins (3a, 3b, 5a, and $5 \mathrm{~b})$ [2]. The disease is manifested by clinical-pathological signs in several tissues, including the respiratory tract, kidneys, gut, oviduct, and testes, resulting in poor performance of egg-laying birds and poor quality of meat. Moreover, the disease can be lethal in several cases [3, 4]. Vaccination is the most reliable approach to control IBV. However, existing vaccines cannot provide effective protection owing to the high frequency of mutations and

(c) The Author(s). 2021 Open Access This article is licensed under a Creative Commons Attribution 4.0 International License, which permits use, sharing, adaptation, distribution and reproduction in any medium or format, as long as you give appropriate credit to the original author(s) and the source, provide a link to the Creative Commons licence, and indicate if changes were made. The images or other third party material in this article are included in the article's Creative Commons licence, unless indicated otherwise in a credit line to the material. If material is not included in the article's Creative Commons licence and your intended use is not permitted by statutory regulation or exceeds the permitted use, you will need to obtain permission directly from the copyright holder. To view a copy of this licence, visit http://creativecommons.org/licenses/by/4.0/ The Creative Commons Public Domain Dedication waiver (http://creativecommons.org/publicdomain/zero/1.0/) applies to the data made available in this article, unless otherwise stated in a credit line to the data. 
recombination of the IBV genome between viruses with large genetic differences. Therefore, commercial vaccines often fail or only provide partial protection against IBVs [5], posing a major challenge to the poultry industry.

Long non-coding RNAs (lncRNAs) are transcripts longer than 200 nucleotides but without proteincoding capacity [6]. LncRNAs are critical regulators of a wide range of biological processes, including cell proliferation, differentiation, apoptosis, autophagy, tissue repair, and remodeling [7]. Several studies have demonstrated that lncRNAs function at the hostpathogen interface to regulate viral infections either by innate immune responses at several levels including activation of pathogen-recognition receptors or by epigenetic, transcriptional, and posttranscriptional effects [8]. For example, the latest research reported that lncRNA Malat1, a negative regulator of antiviral type I IFN (IFN-I) production, suppressed antiviral innate responses by targeting TDP43 activation via the RNA-RBP interactive network [9]. Although the nature of lncRNAs is well characterized in mammals, little is known about their functions in birds, especially in the field of antivirals for poultry [10]. Furthermore, except for loc107051710, IncRNA L11530, and lncRNA L09863 [11, 12], little is known about lncRNA-mediated innate immune response in chicken. The functions of lncRNAs in anti-IBV immune response in chickens remain unclear.

LncRNAs regulate viral infections in multiple ways, such as epigenetic regulation and promotion of viral latency, protein scaffolding and nuclear localization, alternative splicing, and transcriptional regulation of mRNA via miRNA "sponges" [13]. One of the primary mechanisms of functioning of lncRNAs is by competing for shared microRNAs with mRNAs-known as the competing endogenous RNA (ceRNA) hypothesis [14]. We have previously analyzed the miRNAs of IBV-infected chicken kidney tissue and obtained two differentially expressed miRNAs, namely gga-miR-30d and miR-146a$5 p$, which are encoded by chicken chromosomes 1 and 13 , respectively [15]. Next, an in vitro study demonstrated that gga-miR-30d inhibited IBV replication in HD11 cells by targeting USP47 [16], whereas miR-146a$5 p$ promoted IBV replication in HD11 cells by targeting IRAK2 and TNFRSF18 [17].

We further analyzed the expression patterns of lncRNAs and mRNAs in IBV-infected HD11 cells using next-generation high throughput sequencing techniques. Differential expression and co-expression network analysis were conducted to identify interactions between mRNAs and lncRNAs to understand their possible functions in IBV infection. Moreover, a ceRNA network based on gga-miR-30d and miR-146a-5p was established. These results reveal a new data platform to conduct functional studies of chicken lncRNAs and provide valuable information on new therapeutic approaches to control IBV.

\section{Results \\ Replication status of IBV in HD11 cells}

The expression of non-coding RNAs (ncRNAs) in cells is closely related to the stage of virus infection [13]. To confirm the status of IBV in HD11 cells, indirect fluorescent immunoassay (IFA) was performed after IBV infection for 0,36, or $48 \mathrm{~h}$ (Fig. 1). The infection rate of the virus was calculated using the relative ratio of red fluorescence (IBV $\mathrm{N}$ protein) and blue fluorescence (cell nucleus) using ImageJ [18]. The results showed that the virus replication started a little after $36 \mathrm{~h}$ of infection; however, it replicated vigorously after $48 \mathrm{~h}$ of infection (manifested by rupture and collapse of cells, cell aggregation under bright-field microscopy, and significant red fluorescence). No red fluorescence was observed in mock-infected cells. Cytopathies affect the stability of nucleic acids in the cells. Therefore, cells after $36 \mathrm{~h}$ of infection were selected to extract total RNA and build the libraries.

\section{RNA libraries establishment and IncRNA identification}

Total RNA was extracted from $36 \mathrm{~h}$ post-infected HD11 cells (Exp 1, 2, and 3) and mock-infected cells (CK 1, 2, and 3). After high-throughput sequencing, six libraries with an average of 140,317,022 raw reads and 21,047, 553,300 bases were obtained. Nucleotides with a quality value above $30(\mathrm{Q} 30)$ in reads were ranged from 94.09 to $94.4 \%$. After data filtering and quality control, an average of 127,609,381 (90.95\%) clean reads with 19,141, 407,250 high-quality bases were retained. Following the removal of rRNAs, clean reads were mapped to the chicken reference genome. The percentage mapping rates of six libraries ranged from 91.565 to $92.24 \%$ (Table 1).

The lncRNAs were identified as follows (Fig. 2). We used StringTie (version 1.2.4) software to assemble the transcripts based on the comparison results of HISAT2 (version 2.1.0). Transcripts with uncertain strand orientation were removed. The remaining assembled transcripts for lncRNAs were screened for transcripts with length $\geq 200$ nucleotides and exon number $\geq 2$ to obtain 59,930 transcripts. Transcripts whose class-code was $\mathrm{x} /$ $\mathrm{u} / \mathrm{i}$ were screened to obtain 4044 transcripts. Moreover, transcripts with cover $>3$ in at least one sample were screened to obtain 4008 transcripts. We used PLEK (version 1.2), Coding-Non-Coding Index (CNCI; version 2.0), and PfamScan (version 1.6) to analyze the coding potential of candidate lncRNAs. All three software revealed that new transcripts without coding potential were high confidence lncRNAs. Ultimately, 2640 lncRNAs were identified. 


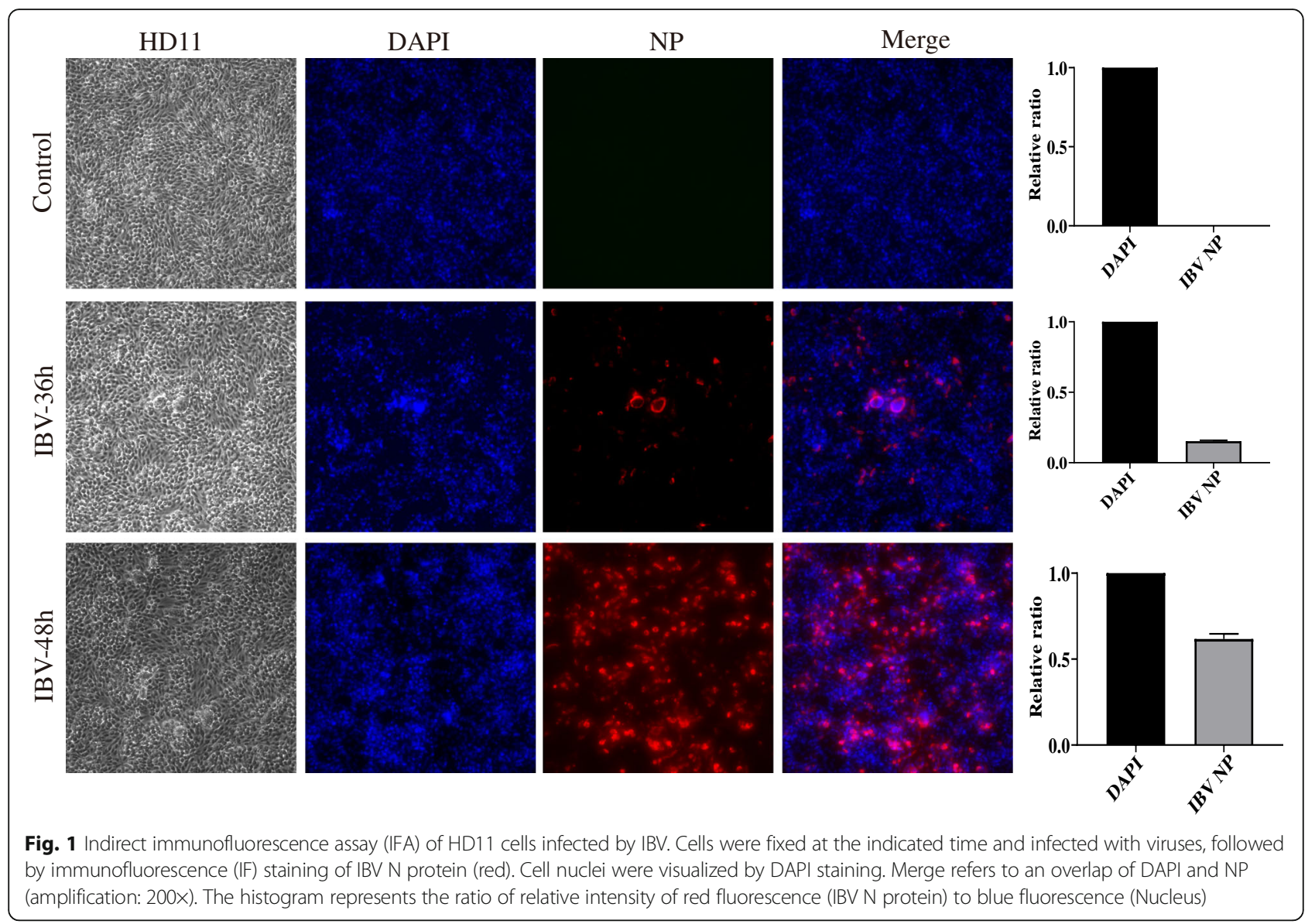

To further identify the characteristics of lncRNAs, we compared predicted IncRNAs with mRNAs for transcript number, length, and exon number (Fig. 3). The result showed that the number of mRNA transcripts was higher than that of lncRNAs. With respect to the transcript length, the predicted lncRNAs were primarily concentrated between 200 and $3000 \mathrm{bp}$, whereas mRNAs were mainly of a length between 1400 and $5000 \mathrm{bp}$. In addition, the majority of lncRNAs contained two to three exons and very few

Table 1 Overview of the RNA sequencing data

\begin{tabular}{|c|c|c|c|c|c|c|c|c|}
\hline Sample & $\begin{array}{l}\text { Raw Data } \\
\text { Reads No. }\end{array}$ & Bases (bp) & Q30 (bp) & $\begin{array}{l}\text { Clean } \\
\text { Reads No }\end{array}$ & $\begin{array}{l}\text { Clean Bases } \\
\text { (bp) }\end{array}$ & $\begin{array}{l}\text { Clean } \\
\text { Reads \% }\end{array}$ & $\begin{array}{l}\text { Genome } \\
\text { Mapping Rate }\end{array}$ & $\begin{array}{l}\text { Sequencing } \\
\text { Mode }\end{array}$ \\
\hline$C-1$ & $\begin{array}{l}150,897 \\
246\end{array}$ & $\begin{array}{l}22,634,586, \\
900\end{array}$ & $\begin{array}{l}21,331,618,679 \\
(94.24 \%)\end{array}$ & $\begin{array}{l}137,417, \\
676\end{array}$ & $\begin{array}{l}20,612,651, \\
400\end{array}$ & 91.06 & $\begin{array}{l}125,822,533 \\
(91.56 \%)\end{array}$ & $\begin{array}{l}\text { Paired-end, } 2 \times 150 \\
\text { bp }\end{array}$ \\
\hline$C-2$ & $\begin{array}{l}137,054, \\
082\end{array}$ & $\begin{array}{l}20,558,112 \\
300\end{array}$ & $\begin{array}{l}19,407,891,463 \\
(94.4 \%)\end{array}$ & $\begin{array}{l}126,612, \\
888\end{array}$ & $\begin{array}{l}18,991,933 \\
200\end{array}$ & 92.38 & $\begin{array}{l}116,736,730 \\
(92.20 \%)\end{array}$ & $\begin{array}{l}\text { Paired-end, } 2 \times 150 \\
\text { bp }\end{array}$ \\
\hline$C-3$ & $\begin{array}{l}138,645 \\
590\end{array}$ & $\begin{array}{l}20,796,838, \\
500\end{array}$ & $\begin{array}{l}19,632,609,578 \\
(94.4 \%)\end{array}$ & $\begin{array}{l}124,766 \\
544\end{array}$ & $\begin{array}{l}18,714,981 \\
600\end{array}$ & 89.98 & $\begin{array}{l}114,421,545 \\
(91.71 \%)\end{array}$ & $\begin{array}{l}\text { Paired-end, } 2 \times 150 \\
\text { bp }\end{array}$ \\
\hline E-1 & $\begin{array}{l}129,518, \\
036\end{array}$ & $\begin{array}{l}19,427,705 \\
400\end{array}$ & $\begin{array}{l}18,289,744,390 \\
(94.14 \%)\end{array}$ & $\begin{array}{l}117,058, \\
784\end{array}$ & $\begin{array}{l}17,558,817 \\
600\end{array}$ & 90.38 & $\begin{array}{l}107,868,528 \\
(92.15 \%)\end{array}$ & $\begin{array}{l}\text { Paired-end, } 2 \times 150 \\
\text { bp }\end{array}$ \\
\hline$E-2$ & $\begin{array}{l}154,994, \\
906\end{array}$ & $\begin{array}{l}23,249,235 \\
900\end{array}$ & $\begin{array}{l}21,875,735,326 \\
(94.09 \%)\end{array}$ & $\begin{array}{l}139,996, \\
898\end{array}$ & $\begin{array}{l}20,999,534 \\
700\end{array}$ & 90.32 & $\begin{array}{l}129,086,227 \\
(92.21 \%)\end{array}$ & $\begin{array}{l}\text { Paired-end, } 2 \times 150 \\
\text { bp }\end{array}$ \\
\hline E-3 & $\begin{array}{l}130,792 \\
272\end{array}$ & $\begin{array}{l}19,618,840 \\
800\end{array}$ & $\begin{array}{l}18,520,223,188 \\
(94.4 \%)\end{array}$ & $\begin{array}{l}119,803, \\
500\end{array}$ & $\begin{array}{l}17,970,525 \\
000\end{array}$ & 91.59 & $\begin{array}{l}110,508,187 \\
(92.24 \%)\end{array}$ & $\begin{array}{l}\text { Paired-end, } 2 \times 150 \\
\text { bp }\end{array}$ \\
\hline Average & $\begin{array}{l}140,317, \\
022\end{array}$ & $\begin{array}{l}21,047,553, \\
300\end{array}$ & $\begin{array}{l}19,842,970,437 \\
(94.27 \%)\end{array}$ & $\begin{array}{l}127,609, \\
381\end{array}$ & $\begin{array}{l}19,141,407, \\
250\end{array}$ & 90.95 & $\begin{array}{l}117,407,291 \\
(92.01 \%)\end{array}$ & \\
\hline
\end{tabular}

Q30: nucleotides with a quality value above 30 in reads

Genome mapping rate: the percentage of reads mapped to the reference genome 


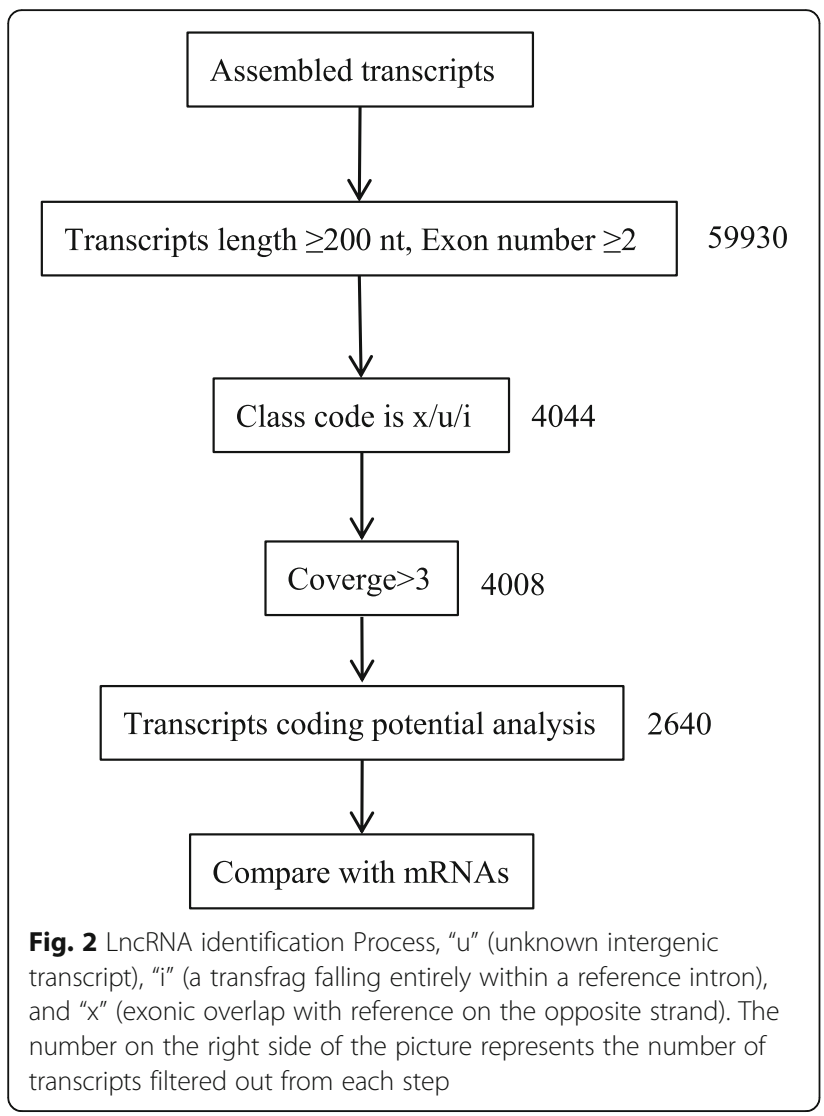

had more than 10 exons. However, the majority of mRNAs contained more than 10 exons. In summary, compared with mRNAs, lncRNAs had fewer and shorter transcripts, and fewer exons.

\section{Expression profiles of IncRNAs and mRNAs in IBV-infected HD11 cells}

In total, we obtained 15,358 mRNAs and 11,510 lncRNAs. Moreover, 153 mRNAs were differentially expressed, with 106 mRNAs significantly up-regulated and 47 mRNAs significantly down-regulated (Additional File 1). In addition, the expression of 181 lncRNAs changed significantly. Among these, 59 lncRNAs were up-regulated and 122 were downregulated (Additional File 2). Heat map and M-A map enrichment analyses (Fig. 4) revealed that compared with the control group, the expression profiles of IncRNAs and mRNAs changed significantly after $36 \mathrm{~h}$ of IBV infection.

\section{LncRNA target gene prediction}

LncRNAs regulate genes in a cis or trans manner. We enumerated the top $10 \mathrm{DE}$ lncRNAs and their possible target genes by searching the gene-encoding protein within $100 \mathrm{~kb}$ upstream and downstream of lncRNAs. These genes were considered potential cis-regulated target genes corresponding to the IncRNAs. For example, SHISA6, located $19,659 \mathrm{bp}$ downstream of MSTRG8180, was considered a potential target gene of MSTRG8180 (Additional File 3). To predict the trans-regulated target genes of lncRNAs, the top $10 \mathrm{DE}$ lncRNAs and 50 most relevant mRNAs were selected to construct the co-expression network of IncRNA-mRNA pairs based on Pearson's correlation coefficient by Cytoscape (Additional File 4). As shown in Fig. 5, the network contained 174 edges. The majority of lncRNAs had multiple target genes, which were related to other lncRNAs, thus forming a large and complex co-expression network.

\section{Pathway analysis of regulated IncRNAs and mRNAs after IBV infection in HD11}

To further explore the functions of these DEGs and DElncRNAs following IBV infection, GO categorization and pathway analyses were performed. Significantly enriched GO terms (top 10 biological processes [BP], top 5 molecular functions [MFs], and top 5 cellular components [CCs]) and KEGG terms for mRNAs and lncRNAs are listed in Fig. 6.

As shown in Fig. 6a, the GO categorization indicated that DEGs were mainly enriched in biological processes of cellular immunity in response to external stimuli. The top three enriched GO terms were related to defense response to other organisms (GO: 0098542), antimicrobial humoral response (GO: 0019730), and flavonoid metabolism (GO: 0009812). Further, GO-MF and GO$\mathrm{CC}$ analyses identified cytosol and transcription factor binding, respectively. Furthermore, the KEGG pathway analysis revealed that the identified mRNAs mainly participated in protein processing in the AGE-RAGE signaling pathway in diabetic complications (ID: gga04933), cytokine-cytokine receptor interaction (ID: gga04060), and arachidonic acid metabolism (ID: gga00590). The top 20 pathways are shown in Fig. 6b.

The GO enrichment analysis of DE lncRNAs showed them to be mainly involved in the regulation of mRNA and RNA binding during IBV replication. For example, the most enriched GO-BP terms were regulation of mRNA binding (GO: 1902415), positive regulation of mRNA binding (GO: 1902416), and positive regulation of RNA binding (GO: 1905216). In addition, several terms directly related to virus infection were found, for example, negative regulation of viral transcription (GO: 0032897 top 6), viral transcription (GO: 0019083 top 11), and regulation of viral transcription (GO: 0046782 top 12). The translation initiation factor binding (GO: 0031369), UDP-glucose 4-epimerase activity (GO: 0003978), glutamate-cysteine ligase activity (GO: 0004357), polysome (GO: 0005844), and glutamate-cysteine ligase complex (GO: 0017109), and viral replication complex (GO: 0019034) were the top three enriched GO-MP and GO-CC terms, respectively (Fig. 6c). The KEGG pathway analysis indicated that lncRNA target 
A

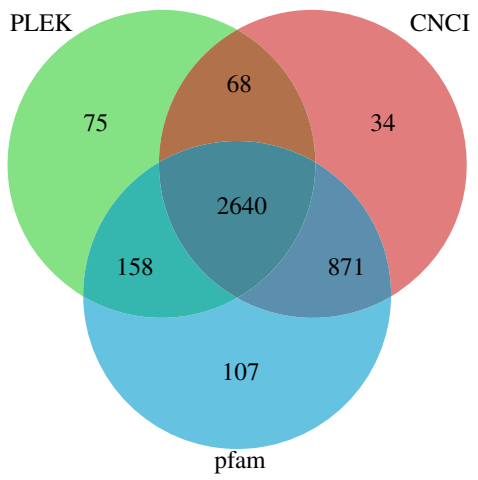

B

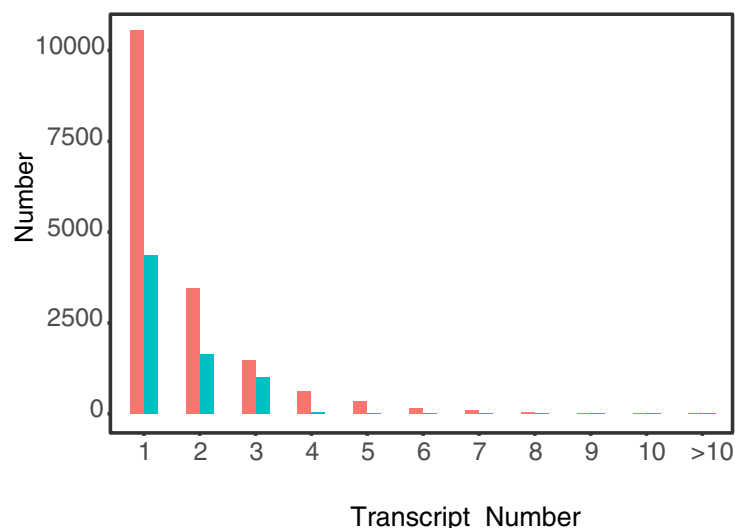

C

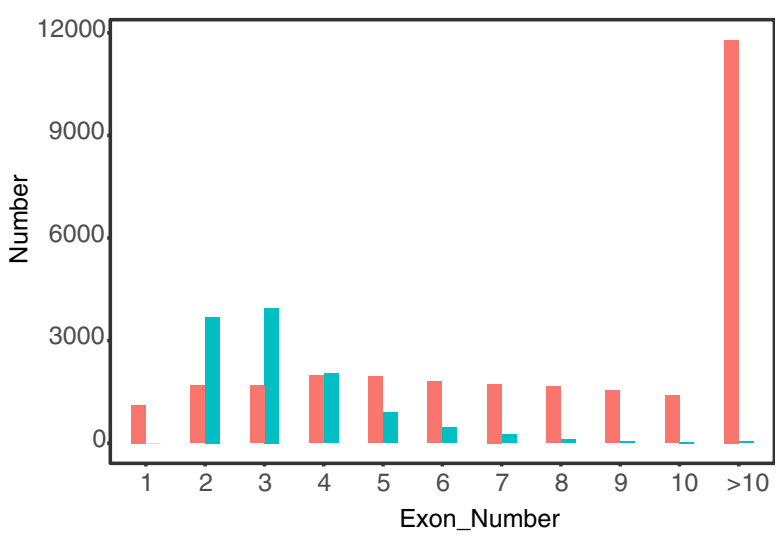

D

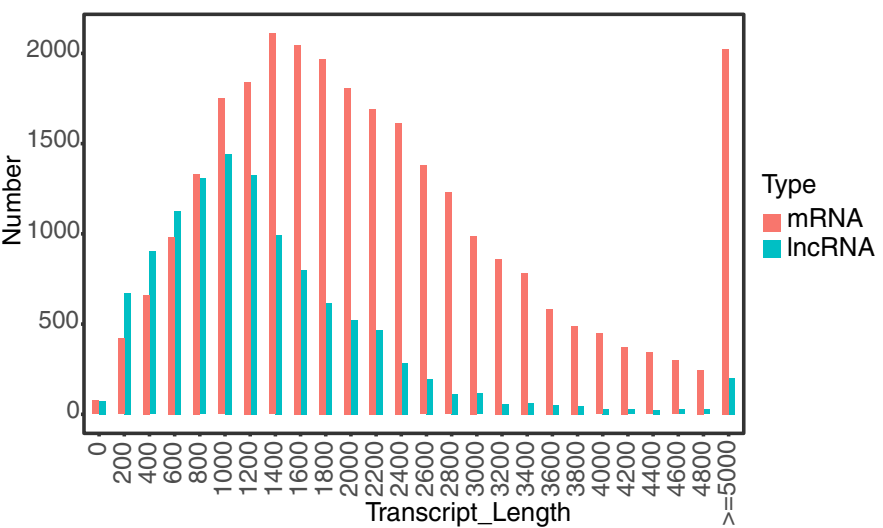

Fig. 3 Prediction and characterization of novel IncRNAs. (A) Three different colored circles represent three different IncRNA prediction software. Overlapping areas of Venn diagrams represent the number of newly identified IncRNAs. (B) Distribution of the number of transcripts in IncRNAs and mRNAs in chicken HD11 cells. (C) Distribution of the number of exons in IncRNAs and mRNAs in chicken HD11 cells. (D) Distribution of transcript lengths in IncRNAs and mRNAs in chicken HD11 cells

genes mainly participated in alanine, aspartate, and glutamate metabolism (gga00250), amino sugar and nucleotide sugar metabolism (gga00520), and sphingolipid metabolism (gga00600). The enrichment pathways are listed in Fig. 6d.

\section{Immune-related mRNA and IncRNA analysis}

Innate immunity is a crucial defense mechanism of cells against viral infections. We screened the DEGs related to innate immunity in HD11 cells infected with IBV for $36 \mathrm{~h}$. These genes included CSF2, IFIT5, IL15, IL1RAPL1, IL22, IL8, MX1, NR1H4, S100A9, SYK, TRAF5, TRIM67, and ZFPM2. Among these, IL15, ILIRAPL1, and SYK were significantly down-regulated, whereas some anti-viral genes, such as IFIT5 and MX1, and some inflammatory factor genes, such as IL8 and IL22, were significantly up-regulated (Additional File 1).
We next analyzed the DE-lncRNAs and screened their target genes related to immunity. We constructed a network diagram using correlation coefficients (Fig. 7) that revealed a complex regulatory network between lncRNAs and immune genes. One lncRNA participated in the regulation of multiple genes in different ways, and one gene was regulated by multiple lncRNAs. For example, IncRNA MSTRG.14220.1 and MSTRG.21445.2 (Additional File 5) were related to at least 10 or $11 \mathrm{im}$ mune genes, and they were speculated to function in immune regulation in HD11 cells.

\section{LncRNA-miRNA-mRNA regulation network analysis}

LncRNAs can affect the gene expression through a variety of strategies [13]. We have previously reported that miR146a-5p and gga-miR-30d had significant regulatory roles in IBV infection in HD11 cells $[16,17]$. We screened for lncRNAs that interacted with miR-146a-5p and gga-miR- 

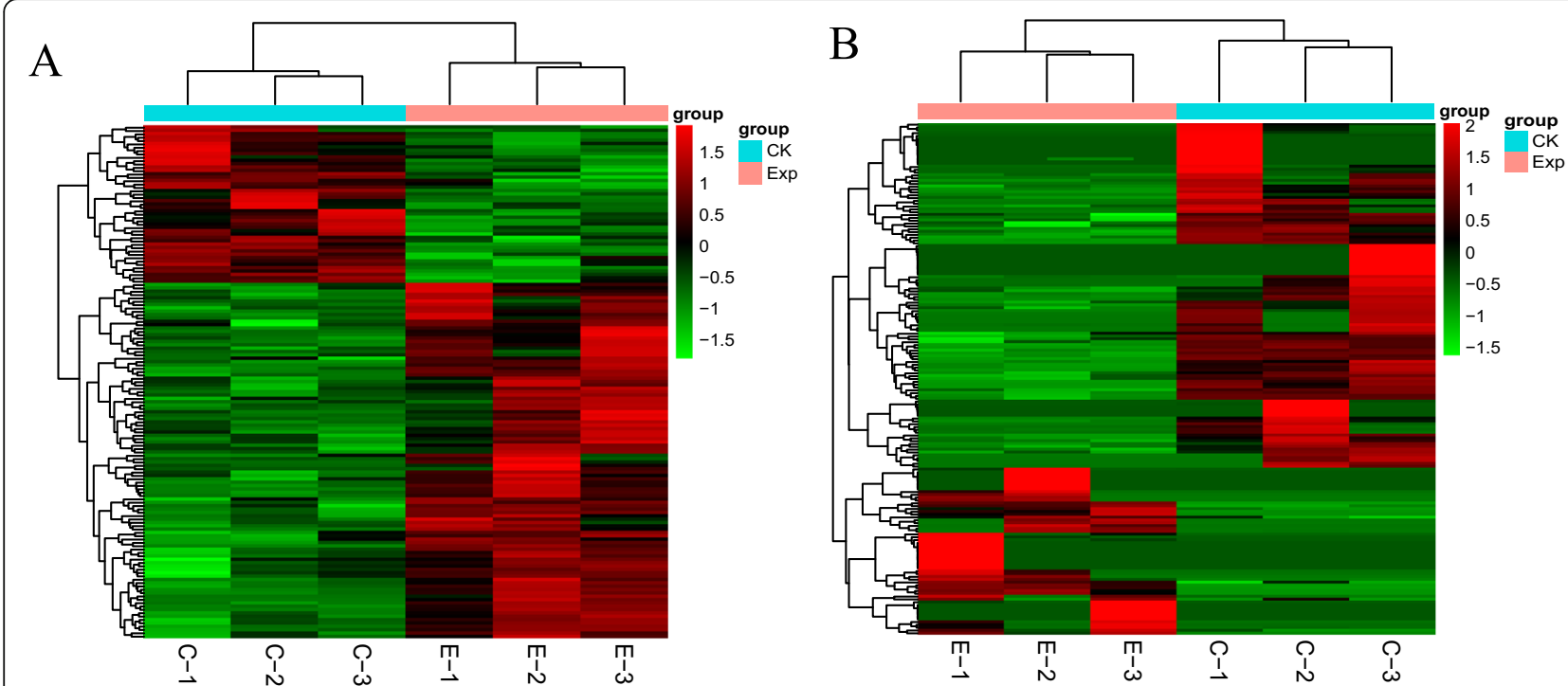

$\mathrm{C}$

D
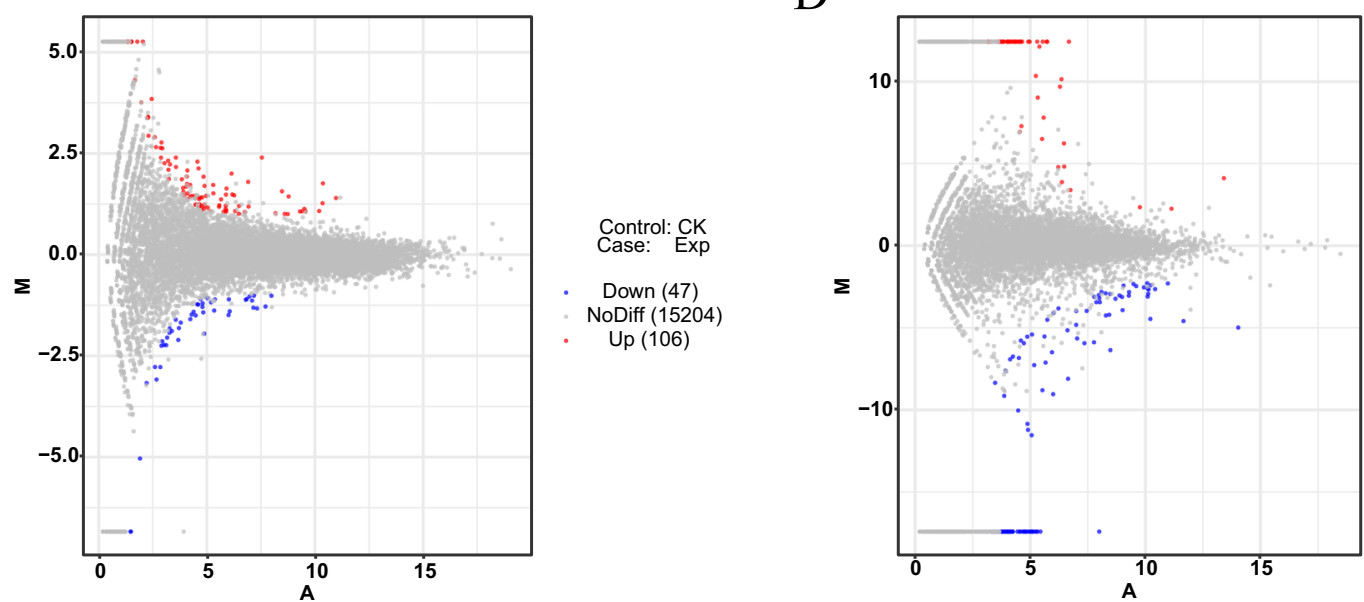

Fig. 4 Differentially expressed genes (DEGs) and differentially expressed (DE) IncRNAs analysis. Exp (IBV infected HD11 cells) vs CK (mock infected HD11 cells) (A, C) Heat map and M-A map for mRNAs expression in control and IBV-stimulated avian HD11 cells at 36 h post-infection. (B, D) Heat map and M-A map for IncRNAs in control and IBV-stimulated avian HD11 cells at $36 \mathrm{~h}$ post-infection

30d. The results revealed 1563 lncRNAs to interact with gga-miR-30d. Among these, 30 lncRNAs were differentially expressed after $36 \mathrm{~h}$ of IBV infection. A total of 1563 lncRNAs were found to interact with miR-146a-5p, and the expression of $32 \mathrm{lncRNAs}$ changed significantly after $36 \mathrm{~h}$ of IBV infection. We constructed a miRNA-mRNAIncRNA interaction network on the basis of potential interactions between them (Fig. 8 and Additional File 6). It is believed that these lncRNAs either function alone or compete for miR-146a-5p and gga-miR-30d with three genes (USP47, IRAK2, and TNFRSF18) to regulate IBV infection. In addition, eight lncRNAs (MSTRG.8180.7, MSTRG.4755.14, MSTRG.22271.3, MSTRG.21445.2, MSTRG.15550.10, ENSGALT00000104335, ENSGALT00 000095670, and ENSGALT00000094718) were found to interact with both miR-146a-5p and gga-miR-30d (Fig. 8).

\section{RT-qPCR validation}

To validate the high-throughput sequencing results, we performed qPCR to detect the expression of lncRNAs and mRNAs in HD11 cells. Five lncRNAs and five mRNAs were selected randomly for $\mathrm{qPCR}$ to determine their relative expression (Table 2). The results are shown in Fig. 9. The qPCR results indicated that the expression patterns of these lncRNAs and mRNAs were consistent with those by RNAsequencing.

\section{Discussion}

The fact that almost all isolated wild-type IBV strains cannot adapt to cell lines restricts their in-depth research [19]. In 2017, Han et al. reported that the IBV Beaudette strain could be serially passaged in HD11 cells 


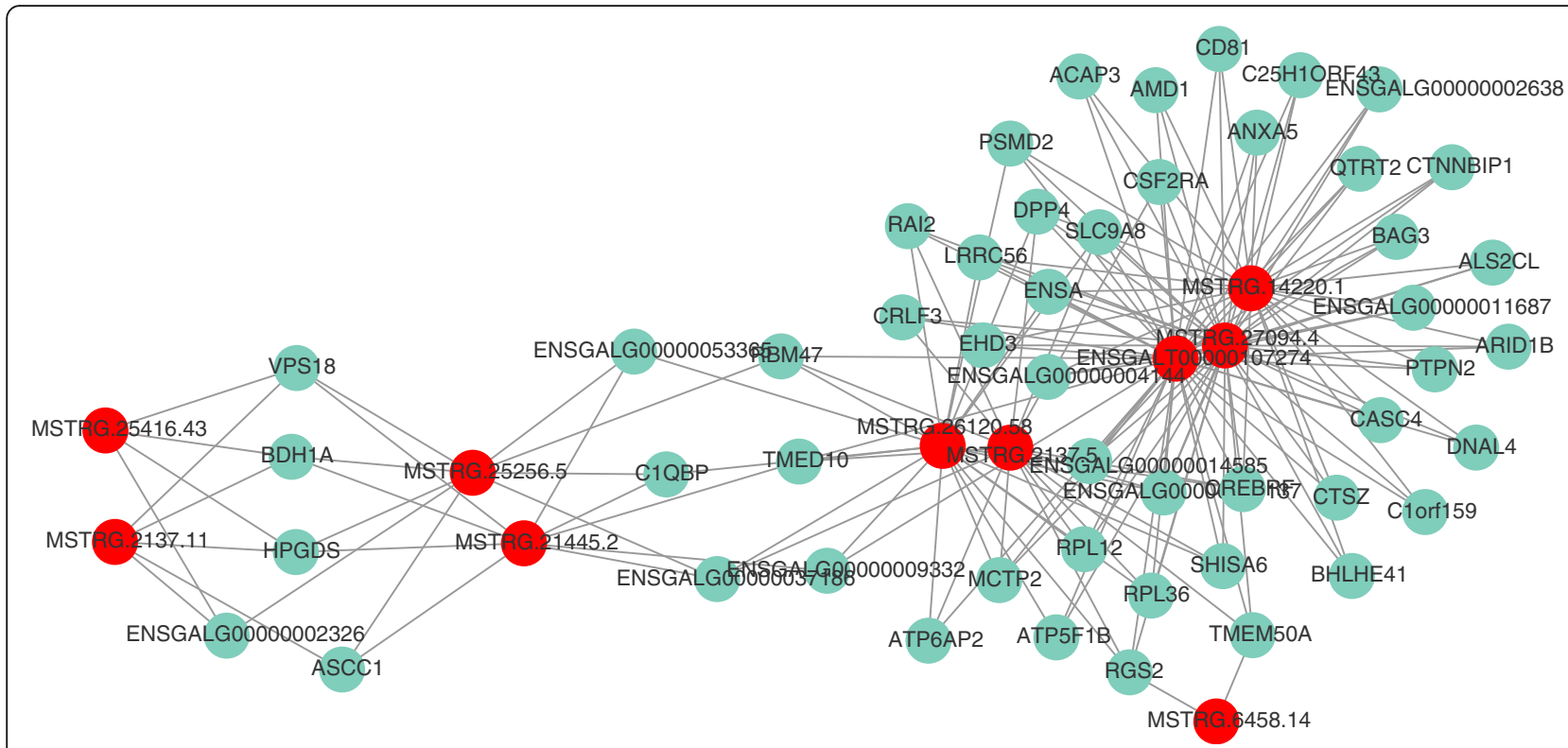

Fig. 5 Co-expression network of DE IncRNAs and mRNAs based on Pearson's correlation coefficient. The top 10 DE IncRNAs and their 50 most frequently altered relative mRNAs with 174 connection edges in IBV-infected HD11 cells are shown. The red node denotes IncRNA and the blue node represents genes

A
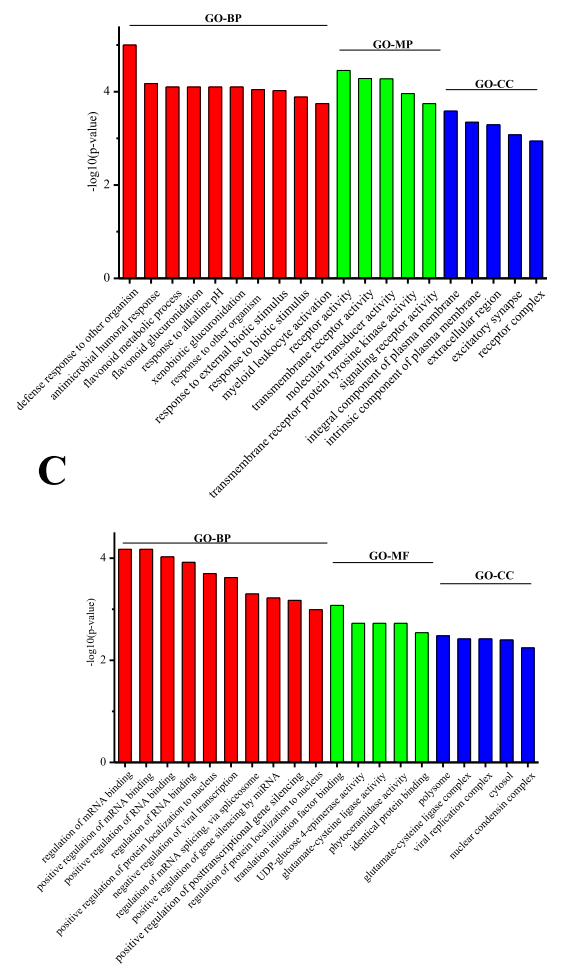

B

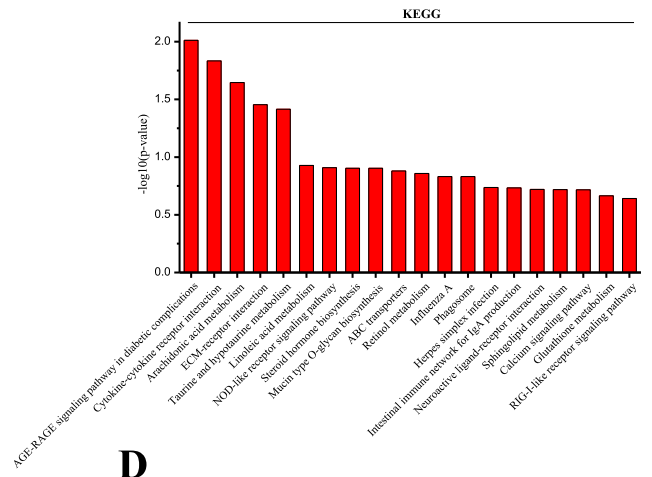

D

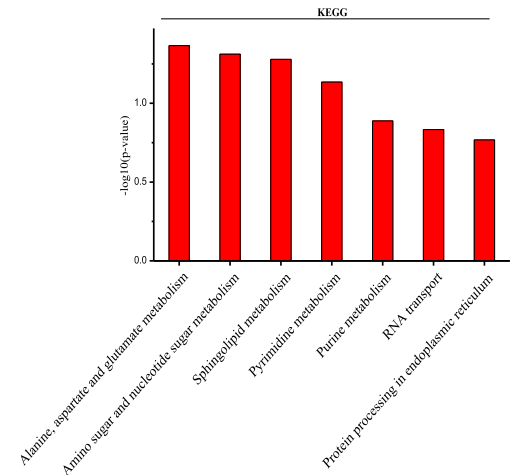

Fig. 6 The GO and KEGG enrichment analyses of DEGs and the target genes of DE IncRNAs. (A) The top 10 GO-BP, 5 GO-MF, and 5 GO-CC terms of DEGs. (B) The top 20 KEGG terms of DEGs. (C) The top 10 GO-BP, 5 GO-MF, and 5 GO-CC terms of DE IncRNAs. (D) The KEGG terms of DE InCRNAs 


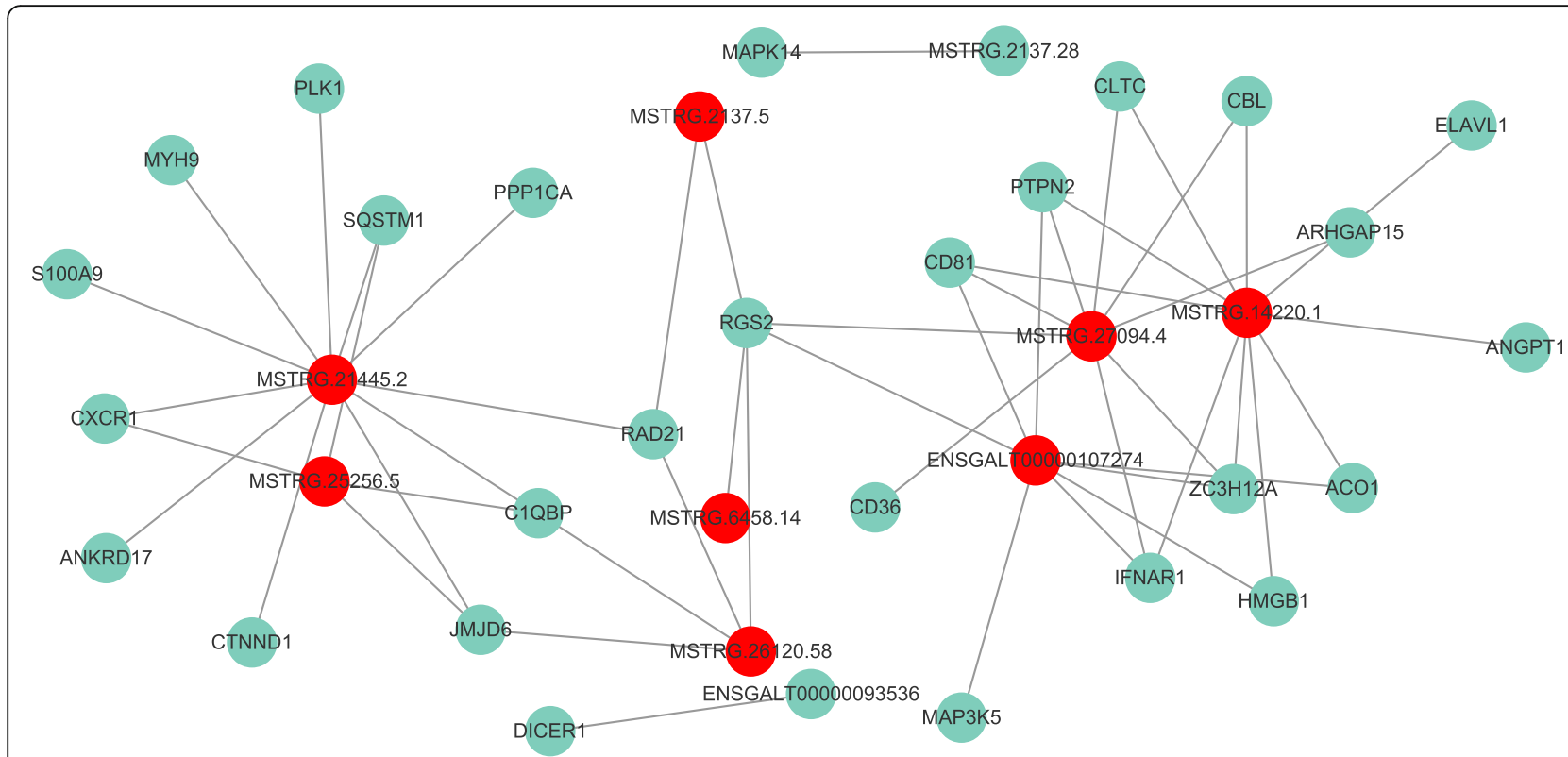

Fig. 7 The interaction network of 10 DE IncRNAs and immune-related targets in IBV-infected chicken HD11 cells. The red node denotes IncRNA and the blue node represents immune-related gene

and triggered cytopathic effects [20]. HD11 is an avian myelocytomatosis virus (MC29) transformed chicken macrophage-like cell line [21]. Because macrophages function in both innate and adaptive immunity [22], it is imperative to study the response of ncRNAs in macrophages to viral stimulation. In the present study, we studied the mRNA-lncRNA regulatory network following IBV infection of HD11 cells.

The development of next-generation, high-throughput sequencing techniques has enabled us to obtain global RNA expression profiling. Recently, several studies have implicated genes and ncRNAs in IBV infection. Cong et al. [23] performed a transcriptome analysis in chicken kidney tissues infected with IBV strain ck/CH/LDL/ 091022. Their results showed that IL6, STAT1, MYD88, IRF1, and NFKB2 as key immune and inflammatory responses genes. We conducted in vitro studies to assess the changes in the expression of genes related to innate immunity in IBV-infected HD11 cells using highthroughput sequencing. The results revealed that certain inflammatory factors (IL15, IL1RAPL1, IL22, and IL8) and some antiviral genes such as IFIT5 and MX1 were differentially expressed following IBV infection. However, in addition to the above genes, the typical signaling pathways for transcriptional activation of chicken IFNs (such as Toll-like receptors), their downstream signaling pathways (such as the JAK/STAT pathway), and interferon-stimulated genes (ISGs) did not change significantly. IBV can use multiple strategies to counteract the IFN response. Certain studies report that IBV delays the activation of the IFN response and inhibits IFN- mediated phosphorylation and translocation of STAT1 [24-26]. We did not detect changes in typical innate immune signaling pathway factors at mRNA levels during the early replication stage of IBV, which could be one of the ways by which IBV escapes the host's innate immunity.

It is reported that certain lncRNAs regulate the expression of immune genes to regulate viral infections. For example, lncRNA NEAT1 is associated with the expression of IL-8, eventually affecting the virus infection [27]. Similarly, the lncRNA BST2/BISPR is induced by IFN and regulates the expression of the antiviral factor tetherin [28]. However, unlike coding genes, IncRNAs are poorly conserved at the level of the primary sequence [13]. Very few lncRNAs related to immunity in chickens have been studied. We studied the lncRNA-related immune response in IBVinfected HD11 cells. LncRNAs, such as IncRNA MSTRG.14220.1 (predicted target genes: ACO1, ELAV L1, CD81, HMGB1, ZC3H12A, ANGPT1, CBL, IFNA R1, CLTC, and PTPN2) and MSTRG.21445.2 (predicted target genes: JMJD6, CXCR1, S100A9, SQST M1, CTNND1, MYH9, ANKRD17, PPP1CA, PLK1, $R A D 21$, and $C 1 Q B P)$, are believed to participate in IBV infection by regulating innate immune response genes.

Screening of lncRNAs and their comparison between virus- and mock-infected cells revealed viral infectionassociated host lncRNAs. In this study, we analyzed the expression patterns of IncRNAs in IBV-infected and mock-infected HD11 cells using RNA sequencing. The 


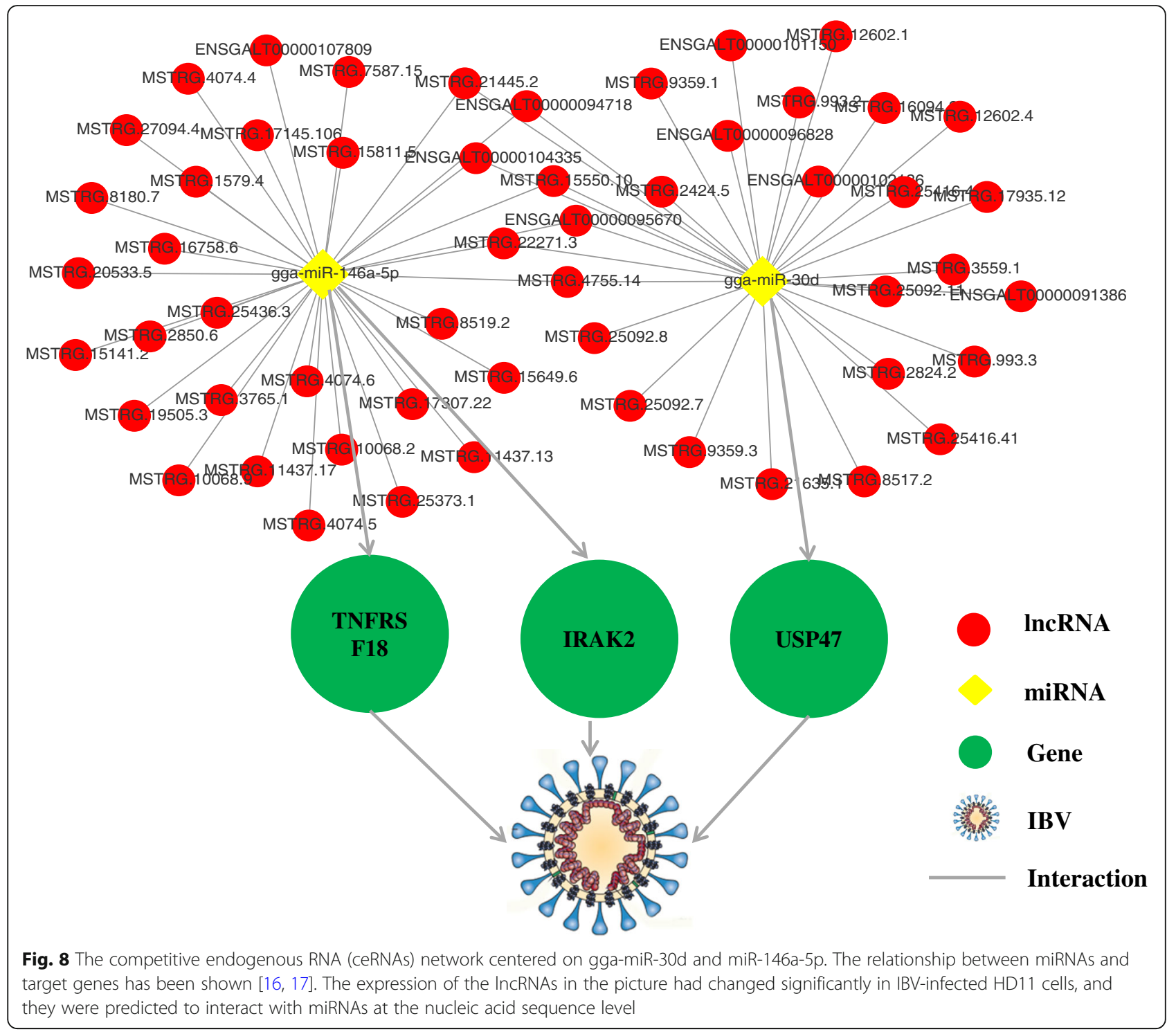

Table 2 Primers for $q P C R$

\begin{tabular}{lll}
\hline mRNA/IncRNA & Forword primer & Reverse primer \\
\hline MSTRG.7587.19 & GACCGTCGTGAGACAGGTTAGT & CTCCTCAGCCAAGCACATACAC \\
MSTRG.22271.3 & GCAACTTCCAGAGACCACAGAA & CTCCAGCCACCAAGCACAAC \\
MSTRG.9359.1 & GCTACCAAGCAATGTGTCCAC & AGTGAGGCAAGTGAGGAGAAGG \\
MSTRG.6458.14 & GGTGTGGTGGTGGACTGTA & AGCCGCACCTGTAGTGAGAC \\
MSTRG.26120.58 & ACGACATTAGGCGGTACGGAAT & GAGGCTGGAGTGGCACAAGA \\
IL22 & CAGGCTCTCAGATCAGGACACT & TTCATCATGTAGCAGCGGTTGT \\
S100A9 & TGGTGAAGTGATGCTCCTGAT & GATGTTGGGTTGGGTTGGT \\
OASL & GGTCAAGCACTGGTACAAGGAG & CAGGCGTAGATGGTCAGCAG \\
CYP3A5 & ACAGCAGAAGGTGGTGAATGAA & GCCATGTCGAGGTATTCCAACT \\
GRID2 & ACTCACATCACCACAACAACCT & TGCCGAAGGAGAAGCCAGAA \\
ChGAPDH & ACTGTCAAGGCTGAGAACGG & GCTGAGGGAGCTGAGATGA \\
\hline
\end{tabular}


A

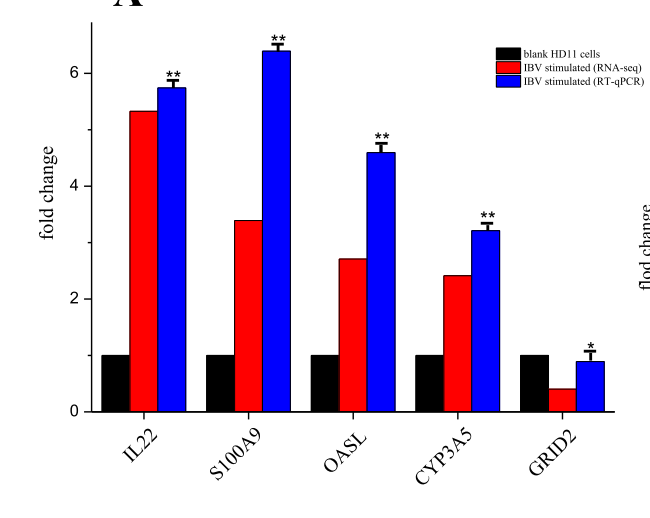

B

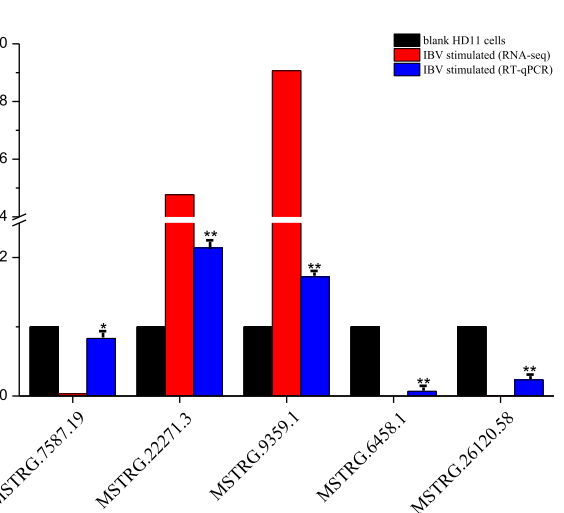

Fig. 9 Results of qPCR analysis of selected mRNAs and IncRNAs. (A) Results of selected mRNAs. (B) Results of selected IncRNAs. All experiments were performed at least in triplicate. Significant differences between the treated and control groups are expressed as ${ }^{*} p<0.05$ and ${ }^{* *} p<0.01$, respectively

results showed 181 lncRNAs to be differentially expressed. Among these, 59 lncRNAs were upregulated and 122 were down-regulated. Interestingly, we found that the majority of DE-lncRNAs, such as MSTRG.25416.43, MSTRG.6458.31, and MSTR G.24743.3, whose target genes (TARDBP, FMR1, and TRIM8) were mainly enriched in terms related to nucleic acid and protein metabolism, and not to terms related to immunity (although certain virus-related terms were also been enriched). The most likely reason could be that nucleic acids and proteins required for virus assembly in the cell are synthesized in large quantities during infection. Protein synthesis in cells is regulated by a variety of factors, including host lncRNAs. We speculated that IBV uses the host's IncRNAs to produce viral nucleic acids and proteins required for replication. Moreover, early studies have demonstrated that the virus hijacks host-encoded lncRNAs to establish persistent infections [29]. Vesicular stomatitis virus, vaccinia virus, and herpes simplex virus 1 could hijack the lncRNA-ACOD1 complex to promote viral replication by activating the metabolic enzyme glutamicoxaloacetic transaminase 2 [30, 31]. Furthermore, IncRNA NeST, Lethe, IncRNA-CMPK2, VIN, and NRON are used by the virus to facilitate infection or susceptibility [32].

The ceRNA hypothesis proposes that transcripts with shared microRNA (miRNA)-binding sites compete for post-transcriptional control. Recently, IncRNA HAND2AS1 was found to work as the ceRNA of miR-3118 to suppress the proliferation and migration in breast cancer by upregulating phlpp2 [33]. LncRNA-Six1 is a target of miR-1611 that functions as a ceRNA to regulate the expression of Six1 protein and fiber type switching in chicken myogenesis [34]. LncRNA MARL functioned as a ceRNA for miR-122 to control protein abundance of
MAVS, thereby inhibiting the SCRV replication and promoting antiviral responses [35]. Previously, we demonstrated that gga-miR-30d inhibited IBV replication in HD11 cells by targeting USP47 [16]. MiR-146a-5p promoted IBV replication in HD11 cells by targeting IRAK2 and TNFRSF18 [17]. We further analyzed the changes in lncRNAs in IBV-infected HD11 cells. Based on gga-miR$30 \mathrm{~d}$ and miR-146a-5p, we constructed the lncRNAmicroRNA-mRNA ceRNA network that provided insights into the interplays in lncRNAs, microRNAs, and mRNAs. For example, lncRNA MSTRG.21445.2, identified as a lncRNA with a length of about $4000 \mathrm{bp}$ in our study, was significantly up-regulated following IBV infection. It is located downstream of the USP47 and overlaps with the pellino E3 ubiquitin protein ligase family member 2 (PELI2) gene on chicken chromosome 5 . The function of PELI2 in innate immunity has already been revealed [36, 37]. LncRNA MSTRG.21445.2 regulates IBV infection by competing with mRNAs of USP47, IRAK2, and TNFRSF18 for gga-miR-30d and miR-146a5 p. Moreover, it may participate in natural immunity against IBV infection by acting on PELI2 alone. Although these results provided new insights for studying the mechanism of IBV infection, bioinformaticsbased predictions should be confirmed using wetlaboratory studies.

\section{Conclusion}

We performed a comprehensive analysis of lncRNA and mRNA expression profiles in HD11 cells following IBV infection using RNA sequencing. We identified more than 2000 novel chicken lncRNAs. In addition, we identified several DE genes that may play pivotal roles in IBV infection using co-expression network analysis. We screened several DE lncRNAs related to IBV replication and cellular immunity, e.g., 
IncRNAs MSTRG.14220.1, MSTRG.21445.2, MSTR G.25416.43, MSTRG.6458.31, and MSTRG.24743.3. Further, we established a ceRNA network centered on gga-miR-30d and miR-146a-5p. We believe our results provide valuable insights into the mechanisms of IBV pathology.

\section{Methods}

\section{Cell culture and virus infection}

The HD11 cell line was kindly provided by Prof. Xin-An Jiao, Yangzhou University. The cells were cultured in Dulbecco's modified Eagle's medium (DMEM, Gemini, USA) supplemented with $10 \%$ fetal bovine serum (FBS, Gemini, USA), $100 \mathrm{IU} / \mathrm{mL}$ penicillin, and $100 \mu \mathrm{g} / \mathrm{mL}$ streptomycin sulfate (Solabio, USA). The IBV Beaudette strain (GenBank: DQ001339) was kindly gifted by Prof. Ding-Xiang Liu, Nanyang Technological University. The cells were infected with the IBV Beaudette strain (multiplicity of infection $[\mathrm{MOI}]=2$ ) and incubated in $5 \% \mathrm{CO}_{2}$ at $37^{\circ} \mathrm{C}$ for $1 \mathrm{~h}$. Following the incubation, the cells were rinsed with phosphate-buffered saline (PBS, Gemini) and cultured at $37^{\circ} \mathrm{C}$ in DMEM supplemented with $2 \%$ FBS $\left(5 \% \mathrm{CO}_{2}\right)$. Controls included cells that were mock infected.

\section{RNA isolation and library construction}

HD11 cells were divided into two groups with three biological replicates in each group: cells infected with IBV represented the experimental group (Exp 1, 2, and 3); mock-infected HD11 cells served as control (CK 1, 2, 3). Following the infection for $36 \mathrm{~h}$, total RNA was prepared from these treatments by the TRIzol method (Invitrogen, USA) according to the manufacturer's protocol. Total RNA quality was assessed on an Agilent 2100 Bioanalyzer (Agilent Technologies, Santa Clara, CA, USA). Sequencing libraries were generated using the rRNAdepleted RNA with NEBNext ${ }^{\circ}$ Ultra $^{\text {Tw }}$ Directional RNA Library Prep Kit for Illumina ${ }^{\circ}$ (NEB, USA) following the manufacturer's recommendations.

\section{Transcript sequencing and genome mapping}

The libraries were paired-end sequenced (PE150, sequencing reads were $150 \mathrm{bp}$ ) at Personal Biotechnology Co., Ltd. (Shanghai, China) using the Illumina HiSeq 2000. The information on the quality of raw data in FASTQ format was calculated, following which the raw data was filtered using Cutadapt (v2.7) software. The clean data were obtained by removing the reads containing the adapter, reads containing poly- $\mathrm{N}$, and lowquality reads. All subsequent analyses were based on high-quality clean data. The chicken genome GRCg6a (GenBank assembly accession: GCA_000002315.5) was used as the reference genome. The reference genome index was constructed by Bowtie 2 (v2.4.1) and the filtered reads were mapped onto the reference genome using HISAT2 (2.1.0), the default mismatch was no more than two. The alignment region distribution of mapped reads was calculated.

\section{Coding potential and conserved analysis of IncRNAs}

First, the raw data were filtered to obtain high-quality clean data. The HISAT2 (2.1.0) software was used to compare the filtered reads with the chicken genome as the reference. Based on the results of HISAT2 (2.1.0), StringTie (v1.2.4) software was used to assemble the transcripts. Transcripts with uncertain directions were removed and lncRNAs were screened in the remaining assembled transcript set using the following steps: (1) Transcripts with length $\geq 200 \mathrm{bp}$ and the number of exons $\geq 2$ were selected. (2) Only transcripts class-coded as "u" (unknown intergenic transcript), "i" (a transfrag falling entirely within a reference intron), and " $x$ " (exonic overlap with reference on the opposite strand) were selected as candidate lncRNAs. (3) LncRNAs with cover $>3$ in at least one sample, that is, those appearing at least thrice in the transcript of one sample, were screened. (4) To further obtain high-confidence lncRNAs, the coding potential of the candidate lncRNA was analyzed using PLEK (1.2), CNCI (v2) and PfamScan (1.6). (5) The mRNAs were compared with predicted IncRNAs in terms of transcript numbers, length, and exon numbers to describe the characteristics of lncRNAs.

\section{LncRNA target gene prediction}

The target gene prediction of lncRNAs was divided into cis-target gene prediction and trans-target gene prediction. We screened for genes with protein-coding capabilities within $100 \mathrm{~kb}$ upstream and downstream of lncRNAs for cis-regulated target genes corresponding to lncRNAs. The target genes with trans-regulation were screened by calculating the expression correlation (Pearson's correlation test) or co-expression analysis method between lncRNAs and mRNAs. We used the correlation coefficient $>0.95$ and $p$-value $<0.05$ to screen the transacting relationship between lncRNAs and mRNAs. Next, the IncRNA-mRNA co-expression network was constructed using Cytoscape.

\section{Identification and bioinformatics analyses of differentially expressed mRNAs and IncRNAs}

StringTie (version 1.2.4) software was used to perform counts at the transcript level to obtain the original expression. Next, FPKM (fragments per kilobase of exon model per million fragments mapped) was used to normalize the expression. In general, FPKM $>1$ demonstrated expression. DESeq was used to analyze the DEGs and DE lncRNAs in IBV-infected and control cells. 
The conditions for screening DEGs were differential expression multiples $\mid \log 2$ FoldChange $\mid>1$, significance $p$-value $<0.05$.

Gene ontology (GO, http://geneontology.org/) and Kyoto encyclopedia of genes and genomes (KEGG, http://www.kegg.jp/) enrichment analyses were performed on DEGs and target genes of DE-lncRNAs. TopGO (2.40.0) was used to map all DEGs and target genes to each term in the GO database; the number of DEGs and target genes for each term was calculated, and the hypergeometric distribution was performed to calculate the DE IncRNA target genes. GO terms with corrected $p$-value $\leq 0.05$ were considered significantly enriched. Similarly, KEGG automatic annotation server (KAAS) was used to perform pathway annotation using the entire genome as the background. The hypergeometric distribution was used to calculate significantly enriched pathways of DEGs and lncRNA target genes, and pathways with a $p$-value $\leq 0.05$ were considered significantly enriched.

\section{Network analysis of miRNAs, IncRNAs, and genes}

LncRNAs can directly bind to the target gene or interact with miRNA as a ceRNA (competitive endogenous RNA) to regulate the expression of the target gene. MiRanda (v3.3a) software was used to predict miRNA target genes. A putative competing endogenous RNA (ceRNA) network was imported to Cytoscape based on the screening of lncRNA-miRNA-mRNA pairs.

Quantitative PCR and indirect immunofluorescence assay Total RNA was isolated using the TRIzol reagent (Invitrogen, USA) and cDNA was synthesized using the PrimeScript RT reagent kit (TaKaRa). RT-qPCR was performed to define the relative mRNA expression of the genes using UltraSYBR Mixture (CWBio, Beijing, China) according to the manufacturer's instructions. Relative fold changes in the gene expression were normalized against chGAPDH using the $2^{-\Delta \Delta C t}$ threshold method. Indirect immunofluorescence assay (IFA) was used to observe the proliferation of the virus. Briefly, IBV-infected or mock-infected HD11 cells were incubated with mouse anti-IBV $\mathrm{N}$ protein monoclonal antibody (Novus Biologicals, USA) at $37^{\circ} \mathrm{C}$ for $2 \mathrm{~h}$. Next, the cells were incubated with a secondary antibody (Alexa Fluor 555-labeled donkey anti-mouse IgG $(\mathrm{H}+\mathrm{L})$, Beyotime) at $37^{\circ} \mathrm{C}$ for $2 \mathrm{~h}$, and stained with DAPI for $10 \mathrm{~min}$ before observing the cells under a fluorescence microscope.

\section{Statistical analysis}

All data were analyzed using Origin 8.1. Multiple groups were compared by one-way analysis of variance (ANOVA) followed by Tukey's multiple comparison tests. Data are expressed as mean \pm standard deviation (SD) of three independent experiments. The $p$-values $<0.05$ were considered significant.

\section{Supplementary Information}

The online version contains supplementary material available at https://doi. org/10.1186/s12864-020-07359-3.

\author{
Additional file 1. Differentially expressed mRNA. \\ Additional file 2. Differentially expressed IncRNA. \\ Additional file 3. Cis-target IncRNA prediction. \\ Additional file 4. Trans-target IncRNA prediction. \\ Additional file 5. Immune related IncRNAs. \\ Additional file 6. IncRNA-miRNA-mRNA network.
}

\section{Abbreviations}

IBV: infectious bronchitis virus; IB: infectious bronchitis; IncRNAs: long noncoding RNAs; ceRNA: competing endogenous RNA; ncRNAs: non-coding RNAs; BP: biological process; CC: cellular component; MF: molecular function; IFA: indirect fluorescent immunoassay; GO: gene ontology; KEGG: Kyoto Encyclopedia of Genes and Genomes; DE: differentially expressed; PELI2: pellino E3 ubiquitin protein ligase family member 2; FPKM: fragments per kilobase of exon model per million reads mapped

\section{Acknowledgements}

Not applicable.

\section{Authors' contributions}

HL: Design, Writing-Original draft preparation; YRZ and LZ: Conceptualization, Methodology; PFC: Software, Figure; WJY and XF: Writing- Reviewing and editing; HNW, CWL and XY *: Supervision, Design. The author(s) read and approved the final manuscript.

\section{Funding}

This research was supported by National Key R\&D Program of China (2017YFD0500703), the Program of Main Livestock Standardized Breeding Technology Research and Demonstration (2016NYZ0052), the Major Science and Technology Special Program of Sichuan Province (2018NZDZX0006), and the Earmarked Fund for Modern Agroindustry Technology Research System (CARS-41-K09)

\section{Availability of data and materials}

Raw RNA-seq data has been deposited into the National Center for Biotechnology Information (NCBI) under the BioProject accession PRJNA659912 (https://www.ncbi.nlm.nih.gov/search/all/?term=PRJNA659912/) and Sequence Read Archive (SRA) database under the accession SRR12543068, SRR12543069, SRR12543070, SRR12543071, SRR12543072, SRR12543073 (https://trace.ncbi.nlm.nih.gov/Traces/sra/?run=SRR12543068).

\section{Ethics approval and consent to participate}

Not applicable.

\section{Consent for publication}

Not applicable.

\section{Competing interests}

The authors declare that they have no competing interests.

Received: 29 August 2020 Accepted: 29 December 2020 Published online: 20 January 2021

\section{References}

1. Cook JKA, Jackwood M, Jones RC. The long view: 40 years of infectious bronchitis research. Avian Pathol. 2012;41(3):239-50.

2. Cavanagh D. Coronavirus avian infectious bronchitis virus. Vet Res. 2007 38(2):281-97. 
3. Xu LW, Han ZX, Jiang L, Sun JF, Zhao Y, Liu SW. Genetic diversity of avian infectious bronchitis virus in China in recent years. Infect Genet Evol. 2018; 66:82-94.

4. Zhou HS, Zhang MH, Tian X, Shao HX, Qian K, Ye JQ, Qin AJ. Identification of a novel recombinant virulent avian infectious bronchitis virus. Vet Microbiol. 2017;199:120-7.

5. Xu LW, Ren MT, Sheng J, Ma TX, Han ZX, Zhao Y, Sun JF, Liu SW. Genetic and biological characteristics of four novel recombinant avian infectious bronchitis viruses isolated in China. Virus Res. 2019;263:87-97.

6. Ponting CP, Oliver PL, Reik W. Evolution and Functions of Long Noncoding RNAs. Cell. 2009;136(4):629-41.

7. Wu WZ, Choi EJ, Lee I, Lee YS, Bao XY: Non-Coding RNAs and Their Role in Respiratory Syncytial Virus (RSV) and Human Metapneumovirus (hMPV) Infections. Viruses-Basel 2020, 12(3)

8. Liu SQ, Liu X, Li J, Zhou H, Carr MJ, Zhang ZJ, Shi WF: Long noncoding RNAs: Novel regulators of virus-host interactions. Rev Med Virol 2019, 29(4).

9. Liu W, Wang Z, Liu L, Yang Z, Liu S, Ma Z, Liu Y, Ma Y, Zhang L, Zhang X, et al. LncRNA Malat1 inhibition of TDP43 cleavage suppresses IRF3-initiated antiviral innate immunity. P Natl Acad Sci USA. 2020;117(38):23695-706.

10. You Z, Zhang Q, Liu C, Song J, Yang N, Lian L. Integrated analysis of IncRNA and mRNA repertoires in Marek's disease infected spleens identifies genes relevant to resistance. Bmc Genomics. 2019;20.

11. Huang XW, Xu YG, Lin QY, Guo WL, Zhao DF, Wang CM, Wang L, Zhou H, Jiang YP, Cui $W$, et al. Determination of antiviral action of long non-coding RNA loc107051710 during infectious bursal disease virus infection due to enhancement of interferon production. Virulence. 2020;11(1):68-79.

12. Bi $Y L$, Yuan $X Y$, Chen $Y$, Chang GB, Chen $G H$. Two new IncRNAs regulate the key immune factor NOD1 and TRAF5 in chicken lymphocyte. J Integr Agr. 2019;18(11):2589-97

13. Lemler DJ, Brochu HN, Yang F, Harrell EA, Peng XX. Elucidating the Role of Host Long Non-Coding RNA during Viral Infection: Challenges and Paths Forward. Vaccines. 2017;5(4).

14. Tay $Y$, Rinn J, Pandolfi PP. The multilayered complexity of ceRNA crosstalk and competition. Nature. 2014;505(7483):344-52

15. Yang X, Gao WQ, Liu H, Li JA, Chen DY, Yuan F, Zhang ZK, Wang HN. MicroRNA transcriptome analysis in chicken kidneys in response to differing virulent infectious bronchitis virus infections. Arch Virol. 2017; 162(11):3397-405

16. Li H, Li JN, Zhai YR, Zhang L, Cui PF, Feng L, Yan WJ, Fu X, Tian YM Wang HN et al: Gga-miR-30d regulates infectious bronchitis virus infection by targeting USP47 in HD11 cells. Microbial Pathogenesis 2020, 141.

17. Liu H, Yang X, Zhang ZK, Zou WC, Wang HN. miR-146a-5p promotes replication of infectious bronchitis virus by targeting IRAK2 and TNFRSF18. Microb Pathogenesis. 2018;120:32-6.

18. Schneider CA, Rasband WS, Eliceiri KW. NIH Image to ImageJ: 25 years of image analysis. Nat Methods. 2012;9(7):671-5.

19. Fang SG, Shen S, Tay FPL, Liu DX. Selection of and recombination between minor variants lead to the adaptation of an avian coronavirus to primate cells. Biochem Bioph Res Co. 2005;336(2):417-23.

20. Han XX, Tian YM, Guan R, Gao WQ, Yang X, Zhou L, Wang HN: Infectious Bronchitis Virus Infection Induces Apoptosis during Replication in Chicken Macrophage HD11 Cells. Viruses-Basel 2017, 9(8).

21. Beug H, Vonkirchbach A, Doderlein G, Conscience JF, Graf T. Chicken Hematopoietic-Cells Transformed by 7 Strains of Defective Avian Leukemia Viruses Display 3 Distinct Phenotypes of Differentiation. Cell. 1979;18(2):375-90.

22. de Geus ED, Vervelde L. Regulation of macrophage and dendritic cell function by pathogens and through immunomodulation in the avian mucosa. Dev Comp Immunol. 2013;41(3):341-51.

23. Cong F, Liu XL, Han ZX, Shao YH, Kong XG, Liu SW. Transcriptome analysis of chicken kidney tissues following coronavirus avian infectious bronchitis virus infection. Bmc Genomics. 2013;14.

24. Kint J, Langereis MA, Maier HJ, Britton P, van Kuppeveld FJ, Koumans J, Wiegertjes GF, Forlenza M. Infectious Bronchitis Coronavirus Limits Interferon Production by Inducing a Host Shutoff That Requires Accessory Protein 5b. J Virol. 2016;90(16):7519-28.

25. Kint J, Dickhout A, Kutter J, Maier HJ, Britton P, Koumans J, Pijlman GP, Fros JJ, Wiegertjes GF, Forlenza M. Infectious Bronchitis Coronavirus Inhibits STAT1 Signaling and Requires Accessory Proteins for Resistance to Type I Interferon Activity. J Virol. 2015;89(23):12047-57.
26. Kint J, Fernandez-Gutierrez M, Maier HJ, Britton P, Langereis MA, Koumans J, Wiegertjes GF, Forlenza M. Activation of the Chicken Type I Interferon Response by Infectious Bronchitis Coronavirus. J Virol. 2015;89(2):1156-67.

27. Imamura K, Imamachi N, Akizuki G, Kumakura M, Kawaguchi A, Nagata K, Kato A, Kawaguchi Y, Sato H, Yoneda M, et al. Long Noncoding RNA NEAT1-Dependent SFPQ Relocation from Promoter Region to Paraspeckle Mediates IL8 Expression upon Immune Stimuli. Mol Cell. 2014;53(3):393-406.

28. Barriocanal M, Camero E, Segura V, Fortes P. Long non-coding RNA BST2/ BISPR is induced by IFN and regulates the expression of the antiviral factor tetherin. Front Immunol. 2015:5:1-13.

29. Kotzin JJ, Mowel WK, Henao-Mejia J. Viruses hijack a host IncRNA to replicate Viruses induce a host IncRNA to rewire cellular metabolism to promote their replication. Science. 2017;358(6366):993-4.

30. Runtsch MC, O'Neill LAJ. GOTcha: IncRNA-ACOD1 targets metabolism during viral infection. Cell Research. 2018;28(2):137-8.

31. Wang P, Xu JF, Wang YJ, Cao XT. An interferon-independent IncRNA promotes viral replication by modulating cellular metabolism. Science. 2017; 358(6366):1051-5.

32. Ouyang J, Hu JY, Chen JL. IncRNAs regulate the innate immune response to viral infection. Wires Rna. 2016;7(1):129-43.

33. Dong GL, Wang XR, Jia Y, Jia YS, Zhao WP, Zhang J, Tong ZS. HAND2-AS1 Works as a ceRNA of miR-3118 to Suppress Proliferation and Migration in Breast Cancer by Upregulating PHLPP2. Biomed Res Int. 2020;2020.

34. Ma MT, Cai BL, Jiang L, Abdalla BA, Li ZH, Nie QH, Zhang XQ. IncRNA-Six1 Is a Target of miR-1611 That Functions as a ceRNA to Regulate Six1 Protein Expression and Fiber Type Switching in Chicken Myogenesis. Cells. 2018; 7(12).

35. Chu Q, Xu TJ, Zheng WW, Chang RJ, Zhang L. Long noncoding RNA MARL regulates antiviral responses through suppression miR-122-dependent MAVS downregulation in lower vertebrates. Plos Pathog. 2020;16(7).

36. Kim TW, Yu MJ, Zhou H, Cui W, Wang JA, DiCorleto P, Fox P, Xiao H, Li XX. Pellino 2 Is critical for Toll-like Receptor/Interleukin-1 Receptor (TLR/IL-1R)-mediated Post-transcriptional Control. J Biol Chem. 2012; 287(30):25686-95.

37. Humphries F, Bergin R, Jackson R, Delagic N, Wang BW, Yang S, Dubois AV, Ingram RJ, Moynagh PN. The E3 ubiquitin ligase Pellino2 mediates priming of the NLRP3 inflammasome. Nature Communications. 2018;9.

\section{Publisher's Note}

Springer Nature remains neutral with regard to jurisdictional claims in published maps and institutional affiliations.

\section{Ready to submit your research? Choose BMC and benefit from:}

- fast, convenient online submission

- thorough peer review by experienced researchers in your field

- rapid publication on acceptance

- support for research data, including large and complex data types

- gold Open Access which fosters wider collaboration and increased citations

- maximum visibility for your research: over $100 \mathrm{M}$ website views per year

At $\mathrm{BMC}$, research is always in progress.

Learn more biomedcentral.com/submission 